\title{
Supporting Blended Learning Using Mobile Instant Messaging Application: Its Effectiveness and Limitations
}

\author{
Wayan Suana \\ Corresponding author, Senior Lecturer, M.Sc., Faculty of Teacher Training and \\ Education, University of Lampung, Bandar Lampung, Indonesia, wsuane@ gmail.com
}

\section{Wayan Distrik}

Asst. Prof., Dr., Faculty of Teacher Training and Education, University of Lampung, Bandar Lampung, Indonesia, wayandistrik8@gmail.com

\section{Kartini Herlina}

Asst. Prof., Dr., Faculty of Teacher Training and Education, University of Lampung, Bandar Lampung, Indonesia, kkartini.herlina@gmail.com

\section{Nengah Maharta}

Asst. Prof., M.Sc., Faculty of Teacher Training and Education, University of Lampung, Bandar Lampung, Indonesia, nengah.maharta@fkip.unila.ac.id

\section{Ni Made Anggi Arlina Putri}

M.Ed., Freelance, Indonesia, nimadeanggi@gmail.com

This paper discusses the effectiveness of mobile instant messaging (MIM) Line in supporting a blended learning model and elaborates students' opinion regarding the limitations of the MIM. A total of 62 pre-service physics teachers were enrolled in an introductory physics course. Line-supported blended learning was implemented in an experiment group whereas learning management system (LMS)based blended learning was as the control group. Data were collected through test, questionnaire, and interview. The test and questionnaire consisted of 20 multiple choice questions and five open-ended questions, respectively. Meanwhile, the interview was a semi-structured interview performed through a focus group interview. The analysis results have given the information that there is no significant difference in the overall improvement of learning outcomes between the two groups. However, students in experiment group have significantly higher improvement of analy $\neg$ sis skills than their counterparts in control group.

Keywords: blended learning, mobile instant messaging (MIM), learning management system (LMS), line application, schoology, students' opinion 


\section{INTRODUCTION}

The growth of technology has drawn the shift of humans' communication from sending letter to email, and using mobile instant messaging (MIM) nowadays. Over the past decade, people known as the net generations frequently use smartphones and tablets for many aspects of their lives. They discuss lessons, socialize, play games, do shopping, and do everything using these tools (Bansal \& Joshi, 2014). The highlight of this phenomenon is the importance of social media application in communication (Kurtz, 2014; Prescott et al., 2013; So, 2016; Sobaih et al., 2016). Currently, social media which includes social networking sites and MIM is considered as one of the most essential communication tools (Abdelraheem \& Ahmed, 2018). In education, social media technology offers modern and creative ways to build social learning environments (Abdelraheem \& Ahmed, 2018). Social media applications can trigger and enhance interaction between instructor and students (Alabdulkareem, 2015; Barhoumi, 2015; Naidoo \& Kopung, 2016; Prescott et al., 2013; Rambe \& Bere, 2013; So, 2016; Sobaih et al., 2016). Due to its essential role, many scholars argued that social media have a great potential as a platform for online teaching and learning.

Regarding its potential in improving learning quality, many scholars have conducted comparative research which was focused on integrating technology in the learning process. An investigation of two virtual platforms, Facebook and a course website, was done by Kurtz (2014) concerning students' perception and participation. This investigation gained that Facebook could foster learners to be actively participating in virtual discussion on Facebook group and sharing knowledge even it was not originally created for educational purposes (Kurtz, 2014). Facebook is also reported having potential to provide social environments in order to improve students' participation in collaborative learning (Al-rahmi et al., 2015; Wang et al., 2012). In addition, enhancing self-confidence, building strong connection and community, facilitating peer and social learning could also be gained by establishing the relationship on Facebook (Sobaih et al., 2016).

Social media may be implemented to support mobile learning (Amry, 2014). The benefits of applying mobile learning are providing students for personalized study, expanding the learning environment to anywhere and anytime (Crescente \& Lee, 2011), lower cost, and smaller size and more lightweight than using computers (Stošić \& Bogdanović, 2013). It is also claimed that by using mobile devices, students can construct and have opportunity to share information and knowledge easily (Pence, 2007). Moreover, Amry (2014) states that mobile devices provide mobility and interactivity of learning for learners. Learners can easily share all vital information such as registration schedule, task, assignment or even examination.

Studies on the use of MIM to support teaching and learning were mostly about WhatsApp. The possible reasons for its popularity are low-cost application, able to send multimedia contents (text, image, audio, video, etc.), easy to use, free downloaded, and providing simple, enjoyable, and accessible communication services (Barhoumi, 2015; Bouhnik \& Deshen, 2014; Tang \& Hew, 2017). Kustijono and Zuhri (2018) had conducted an exploratory-comparative study between Facebook and WhatsApp in order 
to train students' critical thinking in physics teaching. This study found that those tools effectively train students' critical thinking and also get positive responses from the learners (Kustijono \& Zuhri, 2018). Another study about the use of WhatsApp has also discovered some important information. It is claimed that the application could raise students' motivation to actively engage in learning activity (Chipunza, 2013; Plana, 2013). Moreover, by using WhatsApp, the educators can get a better understanding about their students and also create a favorable environment for learning process (Bouhnik \& Deshen, 2014).

Furthermore, the intervention of WhatsApp in mathematics learning on pre-service teachers has also explored by Naidoo and Kopung (2016). The study highlights the facts that, as a resource of learning, WhatsApp provides pre-service teachers chance to engage in meaningful interaction. Moreover, they also argue that this learning tool removes the distance barrier of learners, encourages students to be active and collaborative in learning mathematics, fosters social constructivist learning environment, and builds students' confidence (Naidoo \& Kopung, 2016). This is in line with Bansal and Joshis finding where mobile learning using WhatsApp is very fascinating and educationally working for students. So (2016), in another research, claims that supporting teaching and learning practice using WhatsApp can improve students' learning achievement. The other existing studies have also found that this tool can easily be applied to promote teaching and learning (Alabdulkareem, 2015; Amry, 2014; Rambe \& Bere, 2013).

However, there is a contradicting fact of MIM WhatsApp for an online learning tool. Even though both teachers and students are willing to use WhatsApp in teaching and learning process, practically, they prefer to use it for interaction and other purposes than education (Alabdulkareem, 2015). Another contradicting fact is also presented in a study from Amry (2014). It is found that WhatsApp gives more negative impacts on students' performance than its positive effects (Amry, 2014). The possible reason might be because of its limitations on textual resources of academic conceptualization and unsure within the academic grip of the discussion result using text messages in WhatsApp (Rambe \& Bere, 2013). Therefore, it is a great enthusiasm to explore the strength and weaknesses of another MIM application in sustaining teaching-learning process.

This present study focused on MIM Line as a tool to promote the process of teaching and learning in a blended learning system. Blended learning generally refers to a learning approach that combines face-to-face learning in the classroom with asynchronous and/or synchronous online learning (Wu et al., 2010). Based on the initial information about MIM used by learners as samples, Line was reported as the most frequent MIM used among them for their social communication. This fact brings a view that Line may also have a huge potential to sustaining teaching and learning process. Moreover, there is a special menu in Line group which makes it different from other social platforms such as WhatsApp. Line has Note menu which can be used as a space for class discussions based on each topic and the groups' wall of Line can be used to announce important information dealing with the teaching and learning process. So that, the discussion seems to be well-organized. Therefore, there are two basic problems 
being addressed in this research: (1) is MIM Line effective to support physics teaching and learning process in blended model? (2) What are the limitations of Line as an online learning environment in blended learning model?

\section{METHOD}

\section{Research Design and Procedure}

This research employed a quasi-experiment with pre-test and post-test control group design. The experiment group was taught using MIM Line-supported for blended learning model whereas the control group was taught using LMS-based for blended learning model. The basic version of Schoology was implemented as the online space for control group. The blended learning model used for the two groups, as illustrated in Figure 1, was online learning-face to face learning-online learning in one cycle of learning (Suana et al., 2017). The topic taught in both groups were static electricity during four weeks. It covers electric charge, electrostatic force, electric field, Gauss law, electric potential, work and potential energy of electrostatic, and capacitor. Learning materials provided for both groups included handouts, videos, students' worksheets, and questions for discussion. The learning steps for the two groups followed inquiry learning approach. In the first online activity, students were asked to observe phenomena and ask questions. Then, they discussed it with their peers. At face-to-face, students designed and conducted experiments, analyzed data, and presented the results in groups. They continued learning by reviewing three to five problem through online platform outside of school hour to apply the concepts they had already learned.

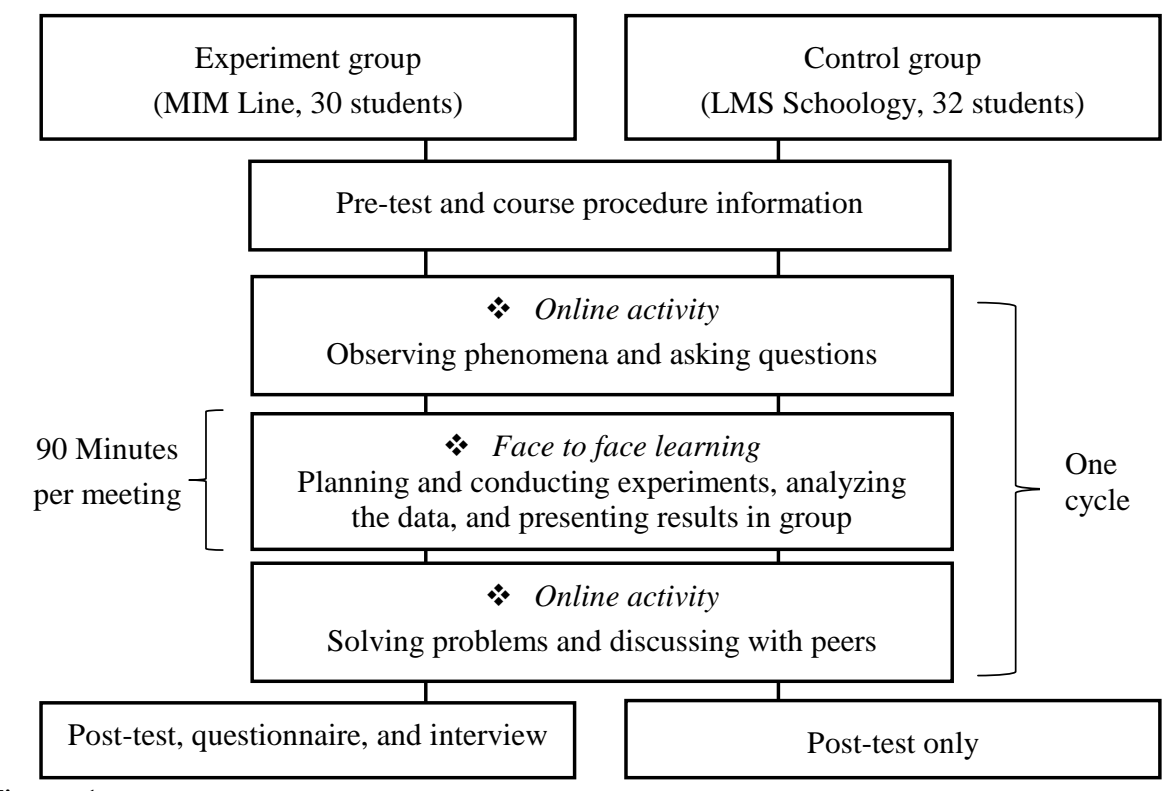

Figure 1

Experiment procedures 


\section{Sample description}

The population of this study was all of the first year students of pre-service physics teacher studying an introductory physics course in the academic year of 2016/2017 in the University of Lampung, Indonesia. The number of population was 62 students, of which 51 of them were girls and 11 were boys and then they were distributed into two classes. Class B $(\mathrm{n}=30)$ was randomly selected as the experiment group while Class A $(n=32)$ as the control group. Both groups had experiences joining a physics course and some other courses in a blended learning model using LMS Schoology prior to this recent research. However, they had never been taught with social media or MIMsupported learning in any courses.

\section{Instruments}

Data were collected through test, questionnaire, and interview. The tests consisted of 20 multiple choice questions which measure students' ability of remembering, understanding, applying, and analyzing of Bloom's taxonomy. It had been validated theoretically by three experts of physics education and fit the criteria of validity. Empirically, the validity and reliability of the test had also been tested to a group of 35 upper students of pre-service physics teachers who had passed introductory physics courses. All of 20 questions were valid and the alpha Cronbach was 0.72 indicating the reliability of the test. The test was distributed to both experiment and control groups before and after the learning process. On the other hand, The questionnaire consisted of five open-ended questions asking students' perception about the strengths, weaknesses, and benefits of using Line in a blended learning context. Meanwhile, the semi-structured interviews were performed through a focus group interview on six students of the experiment group. They were two students for each high, moderate, and low improvement level of learning outcome. The interview result was audio-recorded with respondents' permission and lasted for about one hour. The questionnaire and interview had been evaluated by the three experts to check the appropriateness with the problem targeted. The instruments were subjected to learners in experiment group.

\section{Data Analysis}

To answer the first research question, the quantitative data were analyzed with independent sample t-test for parametric tests and Mann-Whitney U-test for nonparametric tests. Due to the initial ability of the two groups were statistically different, the gain of pre-test to post-test was then analyzed. There were five kinds of gain data; total gain, remembering gain, understanding gain, applying gain, and analyzing gain. The t-test was subjected to data that obeyed normal and homogeneous data distribution whereas data which did not meet those requirements were subjected to Mann-Whitney U-test. The normality test was performed using one sample Kolmogorov-Smirnov test and homogeneity test using Levenes' test. All the statistic tests were conducted using SPSS 20.0 at 0.05 significant level.

To answer the second research question, the qualitative data from questionnaire and interview were analyzed descriptively. Data collected by questionnaire were put on the table according to thematic codes and presented as frequency and percentage form. The 
findings obtained from questionnaire were then matched with interviews of six students in focus group interviews. Samples of interview results which support each of the findings from the questionnaire were then demonstrated to reinforce the findings.

\section{FINDINGS}

\section{Learning Outcome}

This study aimed to test the effectiveness of Line as an online learning platform in blended learning system for Introductory Physics II course. The data of pre-test, posttest, and gain from the experiment and control group are presented in Table 1. At first glance, it appears that the average initial ability of the experimental group is lower than the control group. Nevertheless, the average final ability of the experimental class is slightly higher than the control group. The average gain of experimental group is also higher than the control group. Based on the cognitive level, the experimental groups' average gains were higher at three of four aspects, i.e. remembering (C1), applying (C3), and analyzing (C4) while the control group was better at understanding aspect (C2).

Table 1

Pre-test, post-test, and gain of experiment and control groups

\begin{tabular}{|c|c|c|c|c|c|c|c|c|c|c|c|c|c|c|c|}
\hline \multirow[t]{2}{*}{ Class } & \multirow[t]{2}{*}{$\mathrm{n}$} & \multicolumn{2}{|c|}{ Pre-test } & \multicolumn{2}{|c|}{ Post-test } & \multicolumn{2}{|c|}{ 「otal gain } & \multicolumn{2}{|c|}{$\begin{array}{l}\text { Gain of } \\
\mathrm{C} 1\end{array}$} & \multicolumn{2}{|c|}{$\begin{array}{l}\text { Gain of } \\
\mathrm{C} 2\end{array}$} & \multicolumn{2}{|c|}{$\begin{array}{l}\text { Gain of } \\
\text { C3 }\end{array}$} & \multicolumn{2}{|c|}{$\begin{array}{l}\text { Gain of } \\
\mathrm{C} 4\end{array}$} \\
\hline & & $\overline{\mathrm{x}}$ & SD & $\overline{\mathrm{x}}$ & SD & $\overline{\mathrm{g}}$ & SD & $\overline{\mathrm{g}}$ & SD & $\overline{\mathrm{g}}$ & SD & $\overline{\mathrm{g}}$ & SD & $\overline{\mathrm{g}}$ & SD \\
\hline Experiment 3 & & 37.7 & 11.7 & 57.7 & 12.3 & 20.0 & 14.7 & 11.7 & 27.6 & 16.7 & 25.1 & 14.7 & 33.2 & 36.0 & 27.0 \\
\hline Control & 32 & 41.1 & 7.8 & 56 & 9.8 & 14.8 & 12.8 & 9.4 & 29.6 & 22.9 & 27.4 & 5.6 & 23.4 & 18.8 & 24.9 \\
\hline
\end{tabular}

The normality test results showed that only two gains which were normally distributed, i.e. total and applying gain while remembering, understanding, and analyzing gains were not normally distributed. The results of t-test for the differences of total and applying gain are presented by Table 2 whereas the result of Mann-Whitney U-test for the differences of remembering, understanding, and analyzing gain are explained in Table 3. Table 2 demonstrates that the sig. value of Levenes' test for overall and applying gain was greater than 0.05 which means that they were homogeneous. Thus, they met the criteria of t-test. For t-test result, since their sig. (2-tailed) $>0.05$, this means that there is no difference at applying gain and total gain between experiment and control groups. The same results were obtained at remembering and understanding aspects. Both groups had no significant gain differences in remembering and understanding aspects, as illustrated in Table 3. A different result was only found in analyzing aspect. Since the value of Asymp. sig. (2-tailed) $<0.05$ then there was a significant difference in the analysis ability between the two groups. Students of experiment group outperformed their counterparts.

Table 2

Result of t-test of applying and total gains

\begin{tabular}{|c|c|c|c|c|c|}
\hline \multirow{2}{*}{ Cognitive level } & \multicolumn{2}{|c|}{ Levene's test } & \multicolumn{2}{|l|}{ T-test } & \multirow[b]{2}{*}{ sig. (2-tailed) } \\
\hline & $\mathrm{F}$ & sig. & $\mathrm{t}$ & df & \\
\hline Applying gain & 3.511 & .066 & 1.246 & 60 & .218 \\
\hline Total gain & 1.554 & .217 & 1.477 & 60 & .145 \\
\hline
\end{tabular}


Table 3

Result of Mann-Whitney U-test of remembering, understanding, and analysis gains.

\begin{tabular}{llll}
\hline Cognitive level & Mann-Whitney U & $\mathrm{Z}$ & Asymp. Sig. (2-tailed) \\
\hline Remembering gain & 466.00 & -.205 & .838 \\
\hline Understanding gain & 409.50 & -1.020 & .308 \\
\hline Analysis gain & 297.50 & -2.650 & .008 \\
\hline
\end{tabular}

Therefore, the overall improvement of students' ability between the experiment and control group was the same. These results indicate that MIM Line may be used to organize online learning, especially for online collaborative learning on physics courses at undergraduate level. Learning outcome obtained by students who use Line were as good as they who use LMS Schoology. When reviewed per cognitive level, the use of Line indicates better result in analysis aspect than Schoology usage.

\section{The Strength and Weakness of Using MIM Line}

The data collected through questionnaire and interview were subjected to answer the second research question. The finding is categorized into two parts, the strength and weaknesses of blended learning using Line.

The strength of blended learning using Line

The implementation of MIM Line for blended learning platform instead of LMS Schoology had several advantages. Based on the answer of questionnaire, there are three categories stated by the learners regarding the strength of blended learning using Line application, as illustrated in Table 4.

Table 4

Students' opinions about the strength of blended learning using Line

\begin{tabular}{clll}
\hline \multicolumn{1}{c}{ Theme } & \multicolumn{1}{c}{ Category } & frequency & percentage* \\
\hline Strength & More accessible than using LMS & 23 & 77 \\
\cline { 2 - 4 } & $\begin{array}{l}\text { More practical (can be opened anytime and } \\
\text { anywhere, no log in repetition) }\end{array}$ & 17 & 57 \\
\cline { 2 - 4 } & More convenient & 4 & 13 \\
\cline { 2 - 4 } & Total response/total respondent & $44 / 30$ & \\
\hline
\end{tabular}

*percentage of total respondent

According to Table 4, the majority of students (77\%) stated that Line was more accessible than Schoology. Below are the supporting statements given by students.

S1: "It's easier to access Line, sir... It's easier to open the online class and it could be anywhere. Video posted on Line can also be played automatically. '

S2: When using Schoology, the loading time to access online class was very long... it was significantly different compared to using Line."

Furthermore, in students' opinion, as an online platform, Schoology was more attractive than Line. However, they still preferred using Line to Schoology since the ease of access, as mentioned below.

S3: "Line is already common to use, but Schoology is quite different. We can't see our friends' answers before we submit our own. It is like something new for us. So, it's more interesting. But, we still choose Line, Sir." 
Using Line is also considered more practical by 17 students $(57 \%)$. To get into online class, students did not have to log in over and over once they had already logged in to Line on their mobile phones. In addition, Line could also be opened anywhere via mobile phones, and it was easier to play videos. Below is the citation of interview results that support it.

S2: "When using Schoology, we have to log in everytime we want to get into it.

For Line, we have installed it on our mobile phones, when there is a notification we may open it directly without logging in anymore."

Besides, $4(13 \%)$ students confirmed that discussion on MIM Line was more convenient. They did not feel ashamed or afraid of making mistakes during the discussions. Learners reasoned that they were accustomed to chatting using Line applications than using Schoology. Moreover, Schoology appeared to be a more formal space for them. Because of the ease of access and practicality of Line, experiment group learners declared they entered the online class more frequently. From the average number of posts, experiment group made 3.5 posts per online discussion session, higher than control group made, 3.3 posts. This implies that students of experiment group were more active.

The weaknesses of blended learning using Line

Line usage in sustaining a blended learning format has some limitations. From the answer of questionnaire, it is found that students faced several challenges. Internetrelated problem is the obstacle experienced by most of students, $24(80 \%)$ of them, followed by discussion setting, time management, structure of thread, and text typing problem experienced by less than $25 \%$.

Table 5

Students' opinions about the strength of blended learning using Line

\begin{tabular}{llll}
\hline \multirow{2}{*}{ Theme } & category & frequency & percentage* \\
\hline \multirow{2}{*}{ Weakness } & Internet-related problem & 24 & 80 \\
\cline { 2 - 4 } & Lack of discussion setting & 7 & 23 \\
\cline { 2 - 4 } & Structure of thread & 4 & 13 \\
\cline { 2 - 4 } & Text typing problem & 3 & 10 \\
\cline { 2 - 4 } & Many chat groups & 1 & 3 \\
\cline { 2 - 4 } & Total response/total respondent & $39 / 30$ & \\
\hline
\end{tabular}

*percentage of total respondent

The internet connection problem includes unstable internet connection, suddenly disconnected internet, running out of internet data plans, low phones' battery, and lack of internet facilities. It was known that most students accessed internet via mobile phones, and internet connection was available freely at campus via Wi-Fi connection. However, according to them, the use of Line has reduced their difficulty necessarily due to bad internet connection compared to Schoology usage. As mentioned before, the students in experimental group had experienced using Schoology for the physics course and few other courses. Below are the statements of two respondents when interviewed.

S4: "When using Line, internet is no more a big problem. The problem occurred only when it was blackout, the internet connection of a particular internet provider is disconnected automatically." 
S5: "When using Line, the problem of internet connection is decreasing sir, if we use Schoology, it takes very long time to load ... too long to log in ... ."

The second category of Line limitations is the lack of discussion setting where $23 \%$ students complained about it. Every member can read answers submitted by other members before submitting their own answers. It enables students to read or even cheat the answers. On the other hand, online discussions on Schoology may be arranged so that members can only see other members' answers when they have been posting their own answers. However, this is not always bad. Students who had difficulties in solving problems of online discussions had benefited because they could learn the answers of their friends and then composed their own answers and participated in the collaborative learning forum, as illustrated by the citations below.

S3: "It's easier to discuss on Line group than on Schoology since we can review the other's answers before we submit our own. When our answer is inadequate or incorrect, we can revise it and then upload it on discussion forum."

S4: "For me, I want to understand the materials, I don't just copy our friends' answers, it's more likely for a comparison. When I am uncertain about their answers, I can figure out the correct one on the internet."

Lines' weakness regarding the structure of thread was complained by four $(7 \%)$ students. It is about the answers and comments which were gathered together as one part so made them difficult to distinguish spontaneously. The comments to a particular question are not separated from other posts rather they are all piled up into. An opinion of a student is given as follows.

S6: "All answers and comments gathered together, unlike on Facebook or Schoology. I mean ... it is hard to distinguish which comments belong to mine and which comments for to the others."

The fourth limitation of Line is associated with text typing containing symbols and equations. As a result, learners mostly used photos to submit their answers, comments, or questions. Quotes of students' statement are as follows.

S2: "It's difficult to write answers on Line because there is no equations feature like Microsoft Word ... It is available on Schoology. Finally, we took photos of our answer and upload it in the online class."

Another problem concerned with students who had many chat groups in their Line Application. Sometimes, online class notifications are covered by notifications from other groups so they can pass an activity in an online classroom. Sometimes, the notifications did not appear although there were activities made by other students or lecturer.

\section{DISCUSSION}

This study was established on two main research questions, namely measuring the effectiveness of MIM Line as an online learning platform and exploring both of its strength and weaknesses. For the first aim, the research looked into the intervention of Line to support teaching-learning process and the improvement of students' cognitive outcomes. In comparing the result of overall gain, it was found that both groups indicate the same improvement. Overall, Integration of Line in teaching-learning physics is as effective as using Schoology. Hence, Line, although not addressed as an online learning 
place, is proved to have potential as an online platform in blended learning model as same as Schoology. This finding is in accordance with the past examinations about the potential of MIM applications as blended learning platforms. Kustijono and Zuhri (2018) have proved that it was effective to train students' critical thinking skills. The intervention of MIM could also improve students' learning achievement by increasing students' knowledge on the subject (So, 2016).

The present study confirms that blended learning using Line can foster students' engagement in collaborative discussion and motivate them to do the tasks. Although Line is not initially intended for online learning platforms, it has pedagogy aspects that can be used to share learning materials and information, discuss, and collect assignments. Concomitantly, the same potential of social media such as Facebook as a sustaining platform for teaching and learning process has been declared by several scholars in their papers (Al-Rahmi et al., 2015; Kurtz, 2014; Prescott et al., 2013; Sobaih et al., 2016; Wang et al., 2012). As a MIM, Line is not equipped with all features of standard LMS, for example, quiz, attendance, and grade book. However, compared to other MIMs, such as WhatsApp, besides having a chat wall, Line group also has another menu, namely note. This menu can be applied to arrange separate space of discussion for many topics. On WhatsApp, all of the online activities are done in one place, the chat wall.

On the other hand, this study highlighted a meaningful finding that Line gained better enhancement of analysis aspect of cognitive outcome than Schoology (see Table 3). The possible reasons might be the effect of the convenience, practicality, and ease of collaborative learning environment provided by the tool. In this way, their analysis skills can be fostered autonomous as they involve in collaborative learning. Ataie et al. (2015) revealed that students' responsiveness and critical thinking can be improved through collaborative learning. This is also confirmed by Naidoo and Kopung (2016). They found that the improvement of learners' performance because they were required to work actively and collaboratively in exhibition activity (Naidoo \& Kopung, 2016). Furthermore, when students are inspired, motivated and actively engaged in learning process through different activities and tasks, they will learn effectively (Hussain et al., 2018).

Line offers several advantages to support the online collaborative learning. Based on the students' opinion, Line has three main strength, i.e. more accessible, more practical, and more convenience. Since the accessibility and practicality of Line, students with poor internet connection were very helpful in joining online learning. They could learn anywhere and anytime efficiently using their mobile phones. Notification from MIM Line can be detected quickly when there is a new post. It enables members faster to get into the online classroom and review the existing teaching materials and tasks and engage in collaborative online discussion. This is consistent with the statement of Tang and Hew (2017) that using MIM is more accessible anywhere and communication and interaction is also easier to do than the using LMS. With MIM through mobile phones, users become more easily communicate with their classmates and lecturers anytime and anywhere compared to computers or laptops. The effect is that students in experiment group were more active in terms of the post number. The availability of audio, text, 
image and video facilities integrated into one interface makes MIM a user-friendly application (Tang \& Hew, 2017). In the previous research (Suana et al., 2017), The use of web-based LMS such as Schoology had a significant difficulty related to the students' slow internet connection.

Nevertheless, administering blended learning using Line also has some limitations. The weakness experienced by most students are internet connection problem. Fluctuating and error internet connection, running out of internet data plans, low phones' battery, and lack of internet facilities are obstacles faced by the students. These are typical internet problem in developing countries, such as Indonesia. Surprisingly, no complaint about the speed of internet connection even though a research revealed that bad internet connections are commonplace in Lampung (Suana, 2018). It can be said that the use of Line significantly decreases challenges regarding the internet connection than the use of LMS such as Schoology.

The second most problem complaining by the students is the Lines' lack of discussion setting. In online discussions, all members can read or even cheat their fellows' answers in submitting their own answers. The fact might cause some students to be less motivated in doing their tasks and choose to wait for their friends to answer. However, there was a positive side revealed in this study, students with lower ability to may be helpful in doing the task of online discussion. They can learn the answers of other students that have been uploaded then construct the answer itself. On the contrary, the discussion forum on Schoology may be arranged so that one can only see the others' answers after he/she has already collected their answers. This may also affect the ease of students in attending online learning which ultimately affects the general cognitive abilities improvement and the improvement of the analysis ability of the experiment group was better than the control class. As stated by Litchfield et al. (2007) that the usefulness and convenience of mobile technology are the main factors that affect student participation in online interaction.

Another weakness of Line stated by some students are thread structure problem (13\%) and the problem of typing text (10\%). All answers and comments accumulate into one on the discussion board so make it a little difficult to distinguish between them. This problem could be more severe if the number of members was too large. In this study, experiment groups' members were only 30 students. Unlike Schoology, the answers and comments are well structured. Another disadvantage is the lack of facility to type text containing symbols or mathematical equations. The similar result was stated by Naidoo \& Kopung (2016) that the lack of mathematical symbols was one of the obstacles using MIM in learning mathematics. The use of LMS Schoology also does not mean allowing students to type texts containing equations easily because of the different nature of equation features on Schoology with standard word processors such as Microsoft Office Word (Suana et al., 2017). Besides, physics subject commonly require other representations such as pictures, illustrations, diagrams, and charts that cannot be formed on any LMSs or MIMs. In that case, taking photos is expected the most convenient option for students.

The last difficulty of using Line declared by one student is the interference of other chat groups' notifications. This happens usually for the who have many chat groups. 
Although Line has some limitations, it was not significant in comparison to the advantages provided by Line. Students still chose using Line rather than LMS for online discussion activity due to their poor internet connections and other internet problem. The Impact of Line's accessibility, the average number of posts per online discussion session made by experiment group was higher than control group. Unfortunately, no comparison could be made related to the time spent by the two groups since Line did not have users' time analysis like Schoology has. Time wasted and the effect of Line on the social presence need to be further investigated as the results of a study reveal that MIM can enhance the development of social presence in online interactions (Tang \& Hew, 2017).

\section{CONCLUSION}

The finding of this study indicates that MIM Line is effective to support online learning in a blended learning approach. The use of Line in static electricity topic improves students' cognitive abilities, as well as the use of LMS Schoology in the same learning approach. From the results analysis of four cognitive levels (remembering, understanding, applying, and analysis), both groups experience equal improvement, except for the analysis ability. Students in Line group gain better analysis skills compared to them in Schoology group. This finding may occur due to the accessible and convenient features for collaborative learning provided by Line. Line application is faster to open by using mobile phones and easier to upload and download photos and videos, especially by those who have poor internet connections. Moreover, from students' perception, Line is also more practical to use for online discussion than webbased LMS. However, Line has limitations, such as the limited features for online learning, accumulation of answers and comments, and difficulty of writing equations and symbols. In that case, Schoology is superior to Line.

Based on the findings, applying MIM Line is more recommended in sustaining blended learning system than implementing standard LMS, especially in teaching of higher order thinking skills or in the area with bad internet connection. However, this recent study is limited by the number of samples and the length of periods of implementation. The impact of time spent and social presence were also not examined on student learning outcomes. Besides, the rapid changes that generally occur in mobile applications including Line may also affect its characteristics to the appropriateness of learning goals, as stated by Calvo, Arbiol, and Iglesias (2014). Thus, Further research is needed to gain a broader picture of the advantages and disadvantages of Line in physics or other subjects.

\section{ACKNOWLEDGEMENTS}

The authors acknowledge the valuable support from Asst. Prof. Dr. Chandra Ertikanto, M.Ed. and Asst. Prof. Dr. Undang Rosidin, M.Ed. as the experts in validating the instruments and learning devices. Furthermore, the volunteer participation of Winda Wijayanti and Ignatius Alexandro in collecting and analyzing the data of experts judgement are also highly appreciated. 


\section{REFERENCES}

Amry, A. B. (2014). The impact of WhatsApp mobile social learning on the achievement and attitudes of female students compared with face to face learning in the classroom. European Scientific Journal, ESJ, 10(22), 116-136.

Abdelraheem, A. Y., \& Ahmed, A. M. (2018). The impact of using Mobile Social Network Applications on Students' Social-Life. International Journal of Instruction, 11(2), 1-14.

Alabdulkareem, S. A. (2015). Exploring the use and the impacts of social media on teaching and learning science in Saudi. Procedia-Social and Behavioral Sciences, 182, 213-224.

Al-Rahmi, W. M., Othman, M. S., Yusof, L. M., \& Musa, M. A. (2015). Using social media as a tool for improving academic performance through collaborative learning in Malaysian higher education. Review of European Studies, 7(3), 265-273.

Ataie, F., Shah, A., \& Nazir, M. N. M. (2015). Collaborative learning, using Facebook's page and groups. International Journal of Computer System, 2(2), 47-52.

Bansal, T., \& Joshi, D. (2014). A study of students' experiences of mobile learning. Global Journal of Human-Social Science, 14(4).

Barhoumi, C. (2015). The effectiveness of WhatsApp mobile learning activities guided by activity theory on students' knowledge management. Contemporary Educational Technology, 6(3), 221-238.

Bouhnik, D., \& Deshen, M. (2014). WhatsApp goes to school: mobile instant messaging between teachers and students. Journal of Information Technology Education: Research, 13, 217-231.

Calvo, R., Arbiol, A., \& Iglesias, A. (2014). Are all chats suitable for learning purposes? A study of the required characteristics. Procedia Computer Science, 27, 251-260.

Chipunza, P. R. C. (2013). Using mobile devices to leverage student access to collaboratively- generated resources: A case of WhatsApp instant messaging at a South African University. International Conference on Advanced Information and Communication Technology for Education (ICAICTE 2013).

Crescente, M. L., \& Lee, D. (2011). Critical issues of m-learning: design models, adoption processes, and future trends. Journal of the Chinese Institute of Industrial Engineers, 28(2), 111-123.

Hussain, I., Cakir, O., \& Candeğer, Ü. (2018). Social media as a learning technology for university students. International Journal of Instruction, 11(2), 281-296.

Kurtz, G. (2014). Integrating a facebook group and a course website: the effect on participation and perceptions on learning. The American Journal of Distance Education, 28(4), 253.

Kustijono, R., \& Zuhri, F. (2018). The use of Facebook and WhatsApp application in learning process of physics to train students' critical thinking skills. In IOP Conference 
Series: Materials Science and Engineering (Vol. 296, No. 1, p. 012025). IOP Publishing.

Litchfield, A. J., Dyson, L. E., Lawrence, E. M., \& Bachfischer, A. (2007). Directions for m-learning research to enhance active learning. In Annual Conference of the Australasian Society for Computers in Learning in Tertiary Education. Centre for Educational Development, Nanyang Technological University.

Naidoo, J., \& Kopung, K. J. (2016). Exploring the use of WhatsApp in mathematics learning: A case study. Journal of Communication, 7(2), 266-273.

Rambe, P., \& Bere, A. (2013). Using mobile instant messaging to leverage learner participation and transform pedagogy at a South African University of Technology. British Journal of Educational Technology, 44(4), 544-561.

Pence, H. E. (2007). Preparing for the real Web generation. Journal of Educational Technology Systems, 35(3), 347-356.

Prescott, J., Wilson, S., \& Becket, G. (2013). Facebook use in the learning environment: do students want this?. Learning, Media and Technology, 38(3), 345-350.

Plana, M. G. C., Escofet, M. I. G., Figueras, I. T., Gimeno, A., Appel, C., \& Hopkins, J. (2013). Improving learners' reading skills through instant short messages: A sample study using WhatsApp. 4th World- CALL Conference, Glasgow, 10-13 July 2013.

So, S. (2016). Mobile instant messaging support for teaching and learning in higher education. The Internet and Higher Education, 31, 32-42.

Sobaih, A. E. E., Moustafa, M. A., Ghandforoush, P., \& Khan, M. (2016). To use or not to use? Social media in higher education in developing countries. Computers in Human Behavior, 58, 296-305.

Stošić, L., \& Bogdanović, M. (2013). M-learning-a new form of learning and education. International Journal of Cognitive Research in Science, Engineering and Education (IJCRSEE), 1(2), 114-118.

Suana, W. (2018). Students' internet access, internet self-efficacy, and internet for learning physics: Gender and grade differences. Journal of Technology and Science Education, 8(4), 281-290.

Suana, W., Maharta, N., Nyeneng, I. D., \& Wahyuni, S. (2017). Design And Implementation Of Schoology-Based Blended Learning Media For Basic Physics I Course. Jurnal Pendidikan IPA Indonesia, 6(1), 170-178.

Tang, Y., \& Hew, K. F. (2017). Is mobile instant messaging (MIM) useful in education? Examining its technological, pedagogical, and social affordances. Educational Research Review, 21, 85-104.

Wang, Q., Woo, H. L., Quek, C. L., Yang, Y., \& Liu, M. (2012). Using the Facebook group as a learning management system: An exploratory study. British Journal of Educational Technology, 43(3), 428-438.

Wu, J., Tennyson, R. D., \& Hsia, T. (2010). A study of student satisfaction in a blended e-learning system environment. Computers \& Education, 55(1), 155-164. 